\title{
SISTEMA DE ESPAÇOS LIVRES DA CIDADE DE MACEIÓ
}

\author{
OPEN SPACES SYSTEM OF THE CITY OF MACEIÓ
}

Geraldo Majela Gaudêncio Faria

Professor doutor da Faculdade de Arquitetura e Urbanismo da Universidade Federal de Alagoas (FAUUFAL), Núcleo de Estudos Morfologia dos Espaços Públicos (MEP)

e-mail: ggfaria@gmail.com

\section{Verônica Robalinho Cavalcanti}

Professora doutora da Faculdade de Arquitetura e Urbanismo da Universidade Federal de Alagoas (FAUUFAL), Núcleo de Estudos Morfologia dos Espaços Públicos (MEP)

e-mail:vrobalo@ctec.ufal.br

\section{RESUMO}

Neste trabalho propõe-se uma classificação dos diferentes tipos de espaços que compõem o sistema de espaços livres da cidade de Maceió. Toma-se por referência suas distintas determinações (dinâmica natural, projetos de parcelamento, usos) e características específicas (tamanho, forma, localização). Discutem-se as práticas de sociabilidade que se desenvolvem sobre os espaços livres e faz-se um balanço das ações das sucessivas administrações municipais sobre o sistema na virada do século XXI.

Palavras-chave: Espaços livres, sistema de espaços livres, sociabilidades urbanas, paisagem, sociabilidade pública, diversidade, singularidade.

\begin{abstract}
In this paper we propose a classification for the differents types of spaces that shape the open spaces system in the city of Maceió, capital of the State of Alagoas, Brazil. Their differents determinations (natural dynamic, parcels, functions) and their caracteristics (size, form, distribution) are taken as the analyses references. The sociability pratices developped in open spaces are discussed; also a balance of the latest local's administration actions over this system is examined.
\end{abstract}

Key words: Open spaces, open spaces system, urban sociabilities, landscape, public sociabilities, diversity, singularity.

\section{1 - QUADRO DOS ESPAÇOS LIVRES URBANOS DE MACEIÓ}

A cidade de Maceió, localizada no litoral nordeste do país, latitude $9^{\circ} 40^{\prime} \mathrm{S}$ e longitude $35^{\circ} 42^{\prime} \mathrm{W}$, clima quente e úmido, conta com uma população de quase 900 mil habitantes distribuídos por uma superfície de $233 \mathrm{~km}^{2}$ (cerca de $45 \%$ da área municipal), o que resultaria em uma densidade uniforme hipotética de 38,6 hab./ha. A expressiva presença dos setores de comércio e serviços confere-lhe a principal característica de sua estrutura econômica. Esses setores incluem a administração pública, serviços portuários, atendimento ao consumo de bens e serviços tanto urbanos como dos setores agroindustrial, pecuário, extrativo e turismo, que constituem as bases da economia estadual. À exceção de um grande complexo industrial cloro-químico, o setor industrial 
instalado na cidade é pouco expressivo. $\bigcirc$ quadro social urbano, marcadamente refletido na arquitetura e nos espaços livres da cidade, denuncia uma flagrante situação de imensa desigualdade econômica e política a resultar na estratificação do tecido urbano segundo o princípio da exclusão socioespacial.

espaço construído da cidade é majoritariamente térreo. $\bigcirc$ processo de verticalização ocorre de maneira concentrada nos bairros litorâneos centrais e, de modo limitado, a quatro pavimentos nos conjuntos populares. Quanto aos espaços livres - espaços não-edificados —, estes podem ser classificados nas seguintes categorias:

1. Áreas remanescentes de exploração extrativa, agrícola ou pecuária.

2. Áreas de matas e florestas.

3. Calhas naturais de drenagem (denominadas localmente como "grotas") e falésias ("encostas").

4. Faixas costeiras litorâneas.

5. Margens da laguna Mundaú.

6. Áreas livres urbanas de uso público: ruas, praças e "parques".

7. Áreas privadas e institucionais não-edificadas: servidões e recuos obrigatórios' ${ }^{1}$, glebas e lotes não-ocupados, sítios e chácaras, além de outros usos urbanos com baixa taxa de ocupação dos terrenos (associações recreativas e hotéis-resorts, entre outros usos ou implantações singulares na cidade).

Essas categorias podem ser agrupadas em duas classificações distintas:

1. Quanto ao grau de urbanização: (a) espaços livres urbanizados correspondem àquelas áreas que resultam de empreendimentos legais ou não de parcelamento do solo (incluindo as favelas), implantados total ou parcialmente, inclusive em relação à infra-estrutura e equipamentos, compreendendo as categorias $6 \mathrm{e}$ 7; (b) os ainda não-urbanizados são áreas propícias à urbanização no interior do tecido urbano, ainda não-parceladas, correspondendo à categoria 1 ; (c) os não-urbanizáveis são as áreas não-propícias à expansão do tecido urbano e nelas se incluem as categorias 2 a 5 , incluídas aí grandes áreas de proteção permanente institucionalizadas (APAs e RPPN).

2. Quanto à sua extensão: (a) grandes espaços livres contínuos, aqueles cuja superfície tem importância para o conjunto da cidade, compreendendo aqueles das categorias 1 a 5; (b) os espaços fragmentados e dispersos, cuja relevância ambiental e funcional restringe-se ao entorno imediato, agrupando as categorias 6 e 7.

Para se compreender a localização, conformação e importância desses espaços livres em Maceió é necessário, primeiramente, identificar os condicionantes geomorfológicos que influíram na formação da cidade. De maneira sintética, o relevo da cidade é composto por dois planos: a parte baixa, correspondendo às planícies litorânea e lagunar (faixas costeiras), e a parte alta, formada por baixos planaltos sedimentares, do grupo "barreiras", localmente denominados "tabuleiros", solo permeável, com altitude progredindo de 40 metros junto das falésias do litoral (sudeste) a 120 metros no interior (noroeste) (Figura 1). 


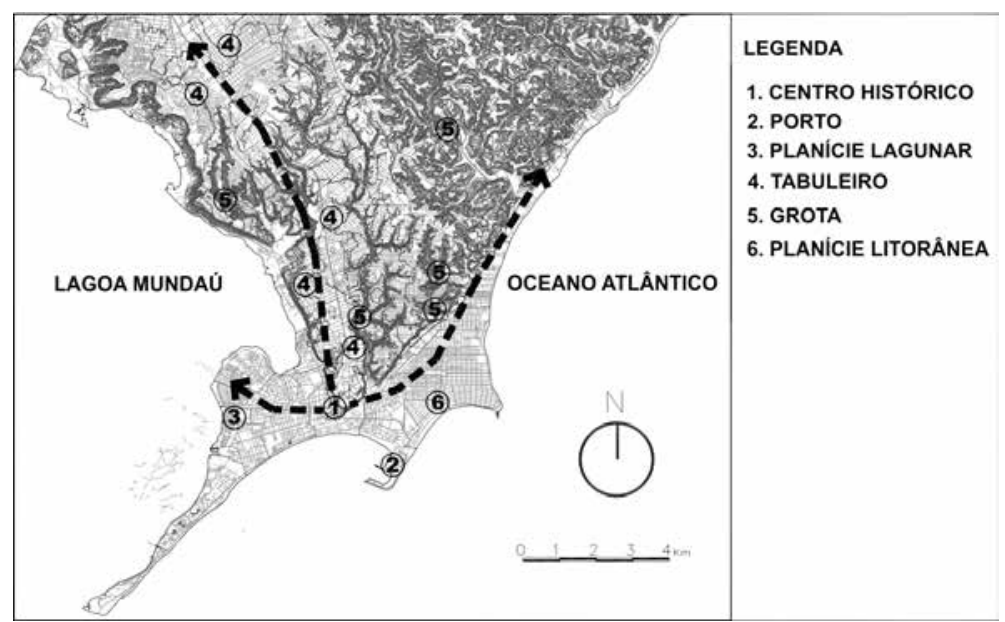

Figura 1:

Maceió: Relevo,

malha viária

e vetores de

crescimento

Fonte: Prefeitura

de Maceió. Base

cartográfica digital,

2000 - Mapa de

declividades

Na cidade, os tabuleiros conformam uma cunha com seu ápice voltado para o sul, de modo que a leste se tem o Oceano e, a oeste, a lagoa Mundaú. Os terrenos do planalto são dessecados de duas maneiras: a) por depressões endorréicas (com alagamentos temporários); e b) por rios e riachos cujas bacias são escavadas em ravinas estreitas de encostas íngremes (grotas), de difícil acesso, desaguando a maior parte no Oceano e uma menor parte na lagoa Mundaú. Desse modo, as "grotas" subdividem os tabuleiros em diversas porções sobre as quais a urbanização "projetada" se desenvolve (parcelamentos, conjuntos e condomínios), assim como as grotas vão abrigando a urbanização "não-projetada", isto é, favelas e loteamentos clandestinos. As bordas externas dos tabuleiros, de onde se descortinam as paisagens lagunar e marítima, descem em falésias íngremes até o plano das planícies costeiras.

Os dois elementos mais marcantes do sítio natural são o Oceano Atlântico, com suas praias, e a lagoa Mundaú. Esta faz parte de um grande "complexo estuarino-lagunar" que se estende por vários municípios da área metropolitana. Esse sistema é constituído

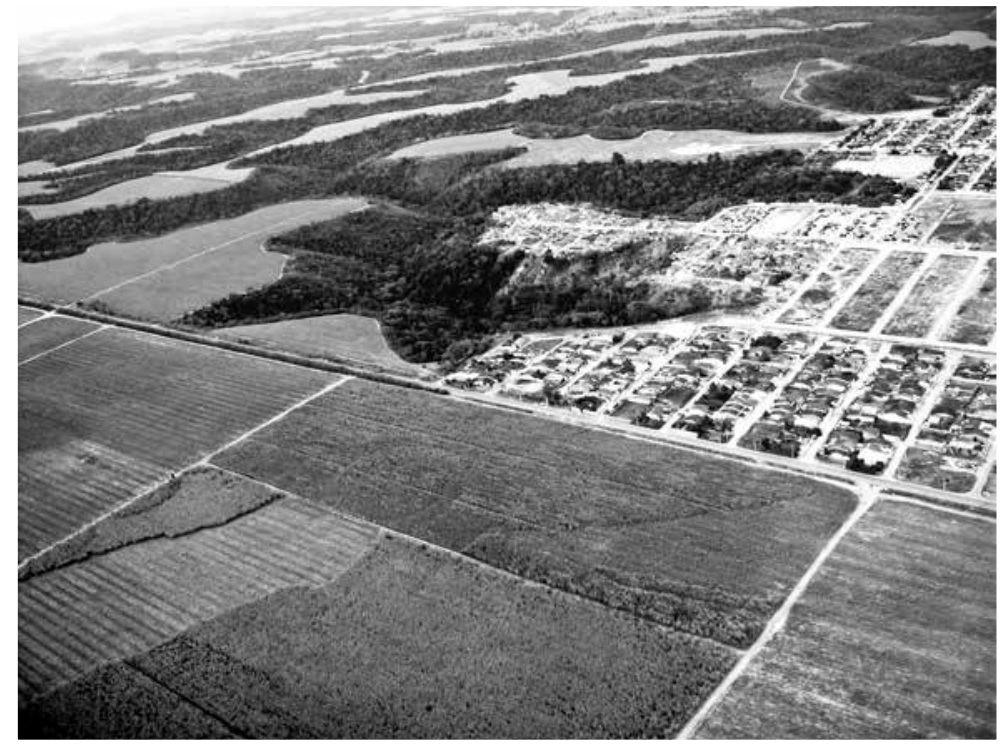

Figura 2: Foto da área de urbanização periférica sobre o tabuleiro, avançando sobre as áreas de cultivo da cana-de-açúcar, contornando as ravinas (grotas) vegetadas ou em processo de ocupação

Créditos: Silvio Macedo, Denis Cossia, Gustavo Meireles, Quapá/USP, dez./2007 
por duas grandes lagunas (Mundaú e Manguaba), resultantes do barramento de três rios - Mundaú, Sumaúma e Paraíba do Meio. As lagunas se conectam entre si e com - Oceano por um complexo de canais por onde suas águas confluem lentamente, ao ritmo das marés e das chuvas, definindo um conjunto de ilhas formadas por depósitos flúvio-marinhos, constituindo um ecossistema bastante particular e importante do ponto de vista paisagístico, biológico e cultural: reprodução de espécies aquáticas, agricultura de subsistência, pesca, artesanato, manifestações culturais, turismo e lazer.

As categorias de espaços livres relacionadas acima podem ser descritas da seguinte maneira:

1. Áreas remanescentes de exploração extrativa, agrícola ou pecuária. São propriedades situadas próximas às bordas e nos interstícios da área urbana, nos tabuleiros e nos vales. Desde a década de 1970 o que restava da antiga Mata Atlântica nos tabuleiros foi retirada, dando lugar ao cultivo da cana-de-açúcar, espécie vegetal monotonamente dominante na área rural, mas esparsamente intercalada com maciços de mata residual, especialmente nas bordas e fundos das calhas-ravinas de drenagem. A paisagem rural, sem a presença de elevações, com monocultura extensiva, tende à monotonia, com variações sazonais caracterizadas ora pela terra nua queimada (pós-colheita e plantio), ora pela massa verde-claro da cana adulta, por vezes pendoada. Na periferia, a urbanização avança, abrindo flancos nas áreas de cultivo (Figura 2).

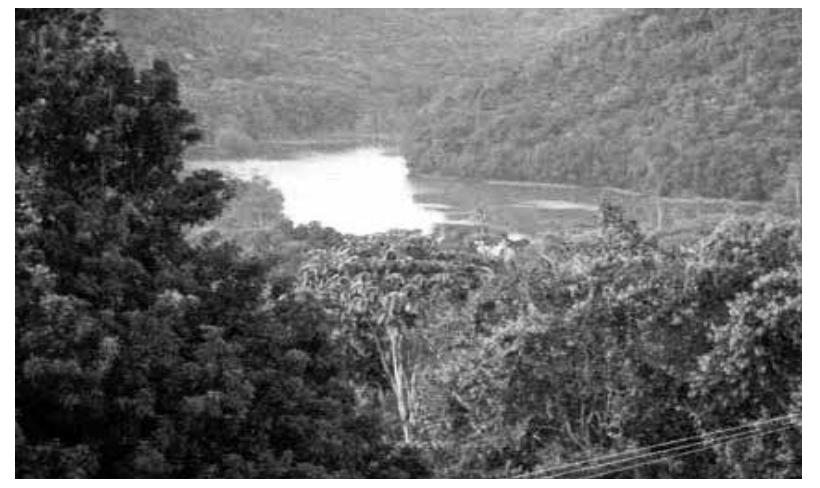

Figura 3:

Mata da APA do Catolé

Crédito: Foto de Geraldo Faria, 2006

2. Áreas de matas e florestas. São remanescentes da antiga cobertura vegetal já bastante explorada que formam, ainda, grandes massas verdes contínuas. As maiores em extensão estão sob a proteção do poder público, como áreas de proteção permanente de dois mananciais periféricos explorados para abastecimento da cidade - Catolé (Figura 3) e Pratagy, estaduais - , além de um Horto Florestal federal (IBAMA) (Figura 4), de 52,9, ha, e de um Parque Municipal (Figura 5), estes dois com mata nativa e também plantio experimental de espécies exóticas (bambu, eucalipto). Apenas a última delas dispõe de infraestrutura para visitação pública. A despeito da fiscalização permanente, todas essas áreas se encontram ameaçadas de ocupação pelas bordas e extração de lenha para uso doméstico. 


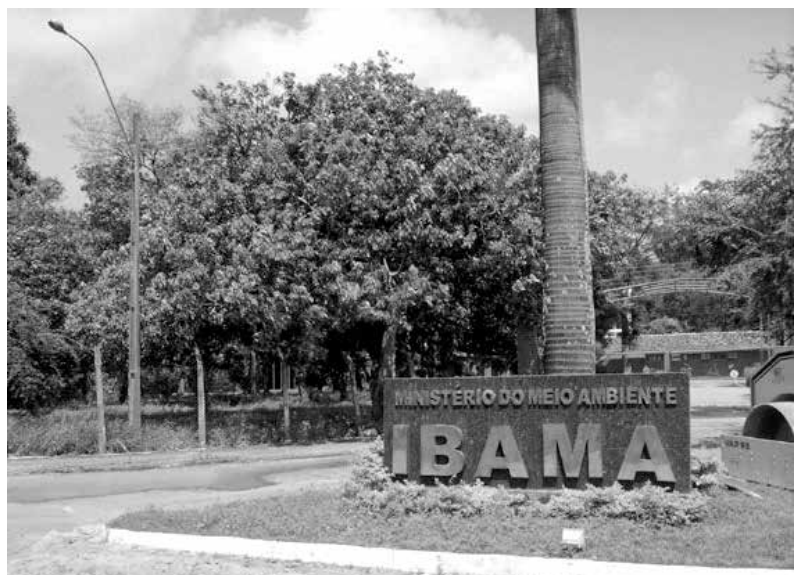

Figura 4:

Horto Florestal do IBAMA

(Tabuleiro)

Crédito: Foto de Geraldo Faria, 2007

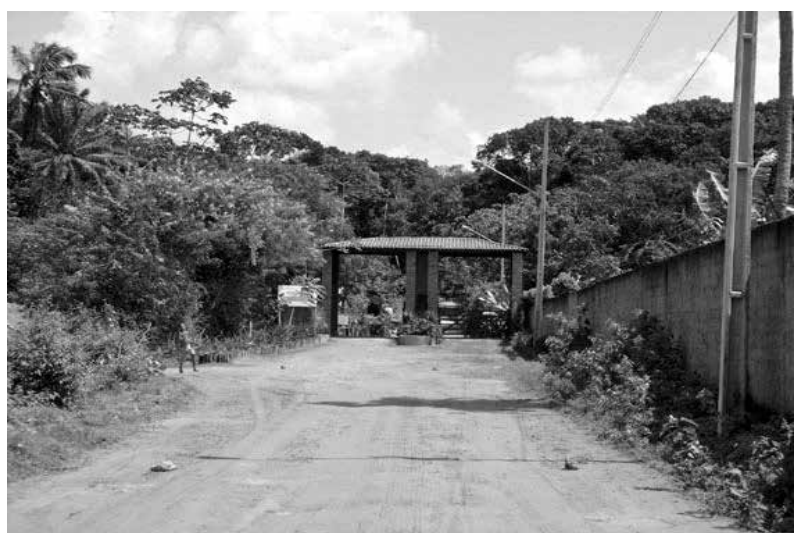

Figura 5:

Parque Municipal (Bebedouro)

Crédito: Foto de Geraldo Faria, 2007

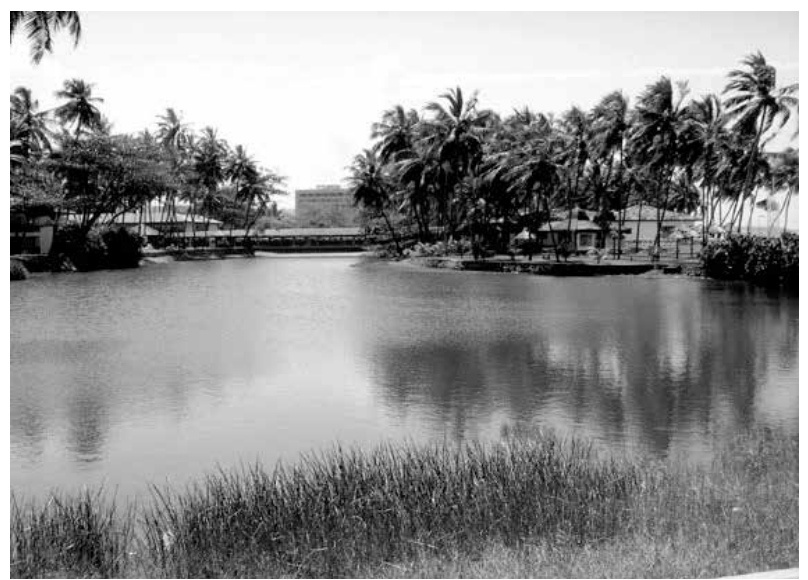

Figura 6:

Lagoa da Anta e Hotel Jatiúca Crédito: Foto de Geraldo Faria, 2007

3. Calhas naturais de drenagem ("grotas") e "encostas". São partes do sistema de drenagem das plataformas dos "tabuleiros", conformando um complexo de cerca de $60 \mathrm{~km}$ de ravinas ou grotas íngremes, estreitas e fundas, ainda parcialmente vegetadas. Algumas das calhas têm fluxo hídrico permanente, outras são temporárias. Em alguns trechos se instalam a pecuária, a silvicultura e a exploração de substrato para aterros. Não obstante protegidas por leis que vedam seu uso com edificações urbanas, elas vêm sendo progressivamente 
ocupadas por favelas e loteamentos. $\bigcirc$ mais central desses sistemas constitui a bacia do riacho Reginaldo, que segmenta os tabuleiros urbanizados em duas grandes porções: oeste e leste, além de delimitar e "isolar" várias outras porções menores do espaço intra-urbano, configurando-as como localidades claramente definidas. A despeito de suas ocorrências em todo o espaço da cidade, de suas características de terrenos impróprios para habitações (risco de deslizamento nas escarpas íngremes e inundação em sua parte baixa) e suas potencialidades em termos paisagísticos e ambientais, as grotas têm sido desprezadas nos projetos de urbanização global ou parcial (parcelamentos), ainda que identificada sua importância estratégica para a conformação do espaço da cidade. Atualmente, as calhas das bacias do Reginaldo e demais riachos das áreas adensadas servem de cloaca para a cidade alta - uma delas drenando o chorume do depósito central de lixo da cidade.

4. Faixas costeiras litorâneas. Estendem-se por $40 \mathrm{~km}$ de restingas e praias, com trechos de recifes lineares e em "calçada" que afloram na baixa-mar. Oceano em tons azul-esverdeados, águas tépidas, praias com vegetação rasteira, predomínio de coqueiros, trechos com restos de dunas, uma pequena laguna (da Anta) (Figura 6), remanescente entre outras que desapareceram aterradas, várias desembocaduras de riachos perenes onde ocorrem formações importantes de mangues. As praias, em sua maior parte diretamente acessíveis por vias costeiras, são, atualmente, as principais áreas de lazer da cidade, especialmente nos fins de semana (Figuras 7a e 7b). As praias de Pajuçara, Ponta Verde e Jatiúca são procuradas para moradia pelas faixas de renda média e alta, já com acentuada verticalização (Figura 8), porém com restrição de gabarito a oito pavimentos mais térreo, em razão de visibilidade do farol costeiro. Em direção ao norte, de Guaxuma a lpioca, localizam-se associações recreativas, instituições estatais, grandes hotéis, restaurantes e antigos loteamentos incorporados para casas de fim de semana, mas, também, pequenos trechos com habitações humildes remanescentes de antigas vilas de pescadores. A área portuária, entre as enseadas do Jaraguá e Pajuçara, desempenhou um papel estratégico na história da província e da cidade, sendo objeto de ações de revitalização e preservação do patrimônio arquitetônico. Mais ao sul, uma estação elevatória da empresa estatal de saneamento lança in natura, por emissário, os efluentes urbanos no Oceano. Domina a paisagem da estreita faixa do Pontal da Barra, ao sul, uma grande indústria cloro-química (Brasken), tendo ela mesma uma área verde implantada e um embarcadouro próprio (Figura 9). Entre a praia de Cruz das Almas, ao norte, e a indústria Brasken, ao sul, a orla litorânea se apresenta como espaços livres urbanizados e contínuos, constituindo um verdadeiro parque linear segmentado apenas pelo porto de Jaraguá. A grande restinga situada na extremidade do Pontal da Barra, área de interação dinâmica entre o complexo estuarino-lagunar e o Oceano, tem sua preservação assegurada pela União. 

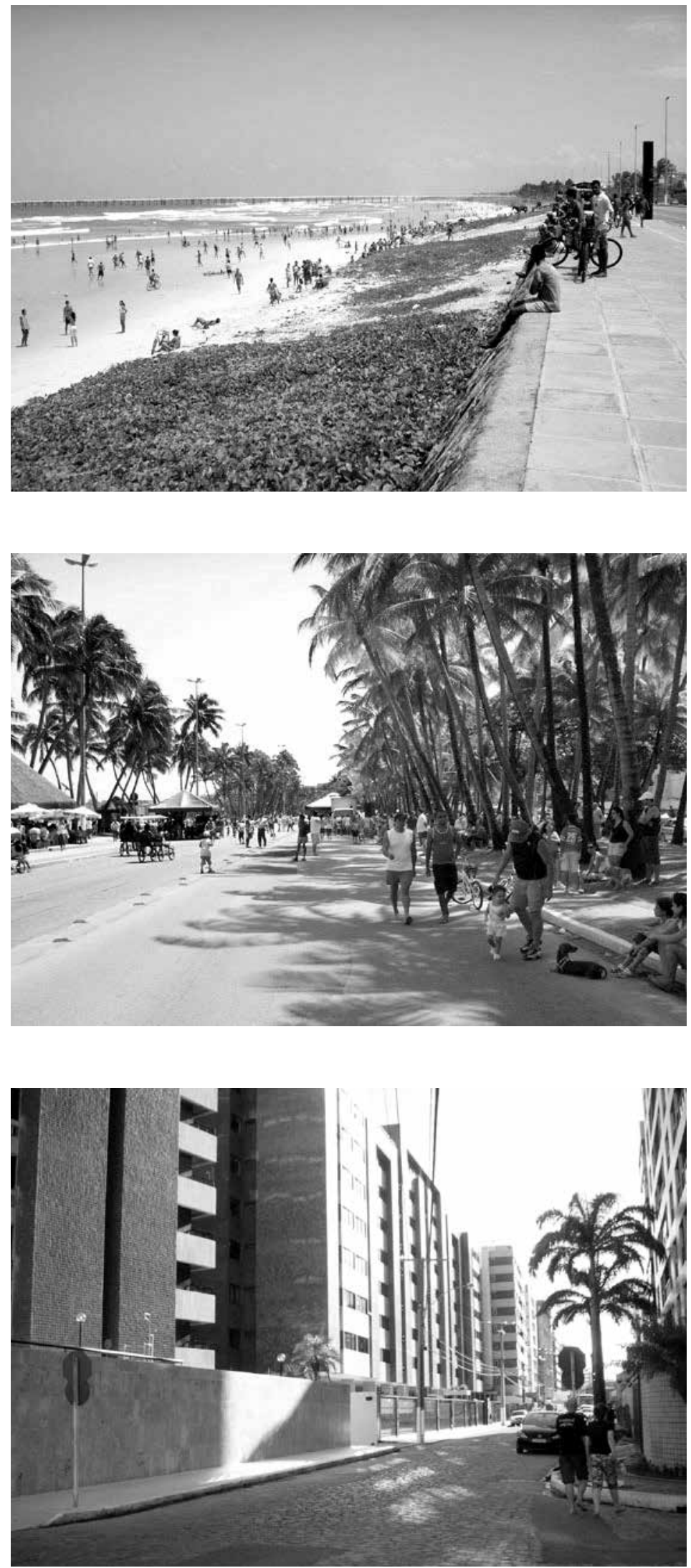

Figura 7a:

Praia do Sobral, orla litorânea sul no domingo

Crédito: Foto de Geraldo Faria, 2007

Figura 7b:

Orla da Pajuçara no domingo Crédito: Foto de Geraldo Faria, 2007

Figura 8:

Bairro de Ponta Verde,

verticalização com ocupação dos recuos

Crédito: Foto de Geraldo Faria, 2008 

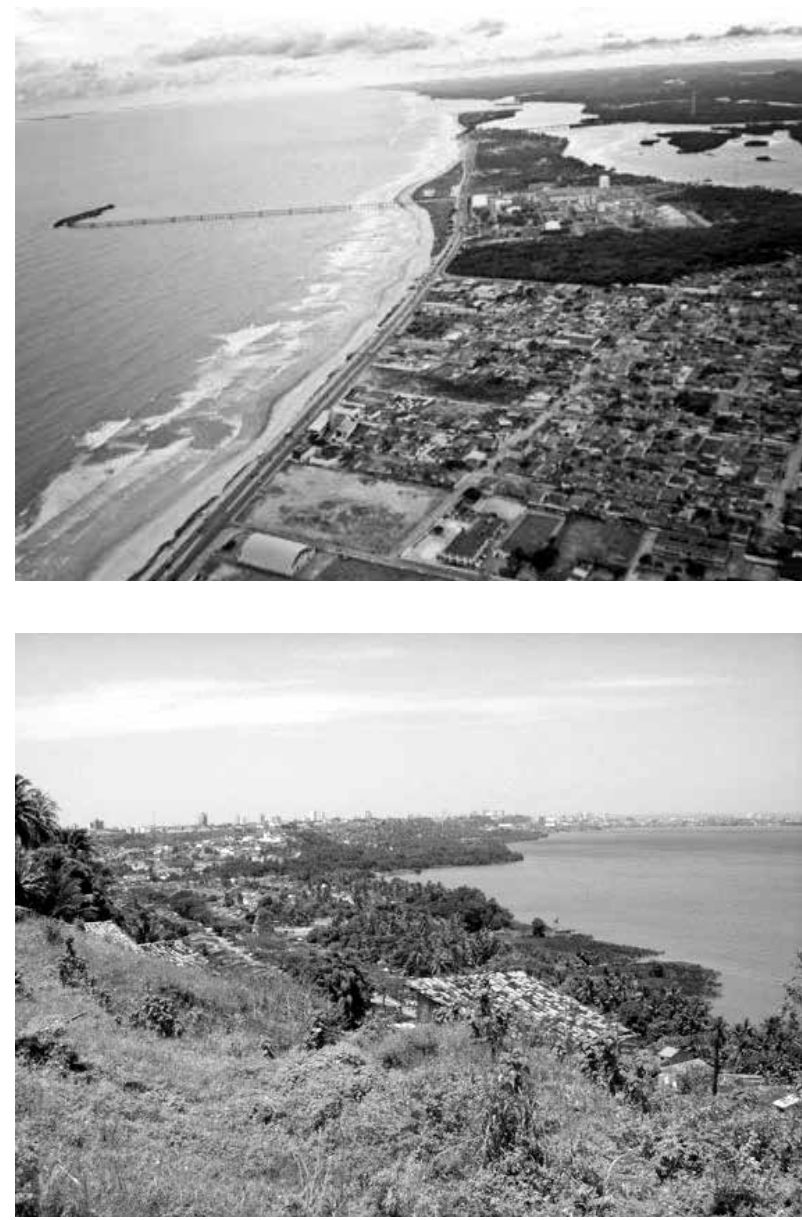

Figura 9:

Praia litoral sul e Pontal da Barra, com a implantação da indústria Brasken

Crédito: Foto de Silvio Macedo, Denis Cossia, Gustavo Meireles, Quapá/USP, dez./2007
Figura 10:

Orla da laguna Mundaú

Crédito: Foto de Geraldo Faria, 2007

5. Terrenos costeiros da laguna Mundaú. Com as faixas costeiras litorâneas, essas áreas formam a parte baixa da cidade. São os terrenos mais recentes, de depósitos flúvio-marinhos. Nas proximidades do centro a orla lagunar em Maceió é densamente ocupada, habitada por população de baixa renda, ocorrendo formação de favelas em palafitas e aterros ilegais que avançam sobre a lagoa. Esses terrenos recebem menos atenção do poder público do que as demais áreas da cidade. Sua parte mais nova, peninsular, foi modificada com diversas ações urbanísticas: construção do dique-estrada, avenida de contorno, áreas de lazer, colônias de pescadores, ajardinamento, conjuntos habitacionais populares. Em sua parte mais antiga, Bebedouro, entrada sudoeste da cidade, localizavam-se fábricas têxteis e sítios burgueses, conservando, ainda, pequenos arrabaldes ribeirinhos e sedes de algumas instituições públicas. A despeito da intensa urbanização em alguns trechos, a natureza ainda está presente em grande parte das paisagens, com domínio da lagoa Mundaú (Figura 10) e de manguezais, emolduradas pelas falésias não-urbanizáveis dos tabuleiros ainda com massas vegetadas que fazem parte da APA Fernão Velho-Catolé.

6. Áreas livres urbanas de uso público. São as áreas livres institucionalizadas como áreas de uso coletivo ou público e cumprem as funções: (a) assegurar e ordenar 


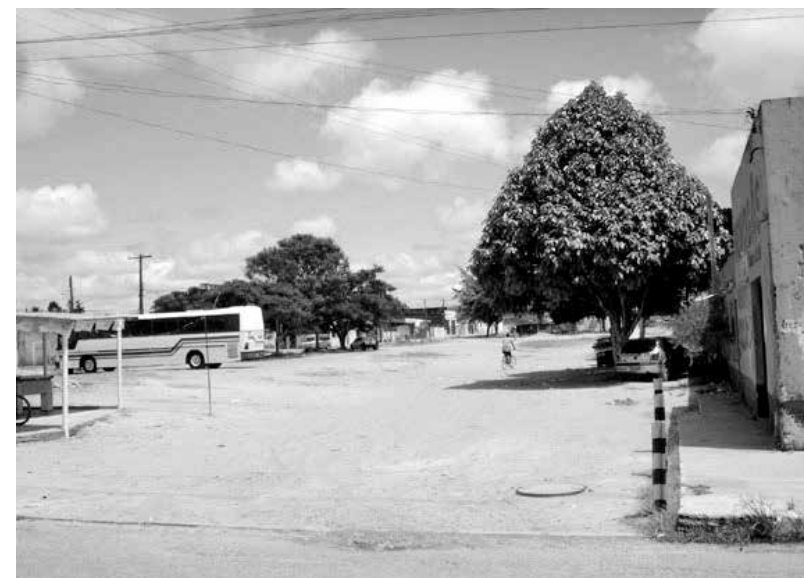

Figura 11:

Grande área livre do Conjunto Habitacional Eustáquio Gomes

Fonte: Geraldo Faria, 2006

o deslocamento ou desfile de pessoas e seus pertences no espaço (ruas, avenidas, estradas, bulevares); (b) recreação e lazer; (c) embelezamento e proteção ambiental (praças e "parques"). Vejamos suas conformações particulares:

a) As ruas. O sistema viário de Maceió resultou do parcelamento do solo realizado às margens dos principais caminhos de entrada e saída da cidade. Assim também foram se constituindo as localidades intra-urbanas que, pouco a pouco, foram adquirindo personalidade e transformando-se em bairros. A maior parte das centralidades de Maceió situa-se em trechos de avenidas ou vias principais, transformadas em "zonas" ou "corredores de atividades múltiplas", apresentando tendência de saturação de tráfego com a invasão das calçadas para estacionamento. A estrutura viária principal superpõe funções de trânsito local e regional, resultando em fluxos e conexões que assumem mais a forma de arborescência do que de redes ou malhas. Os principais eixos rodoviários de acesso à cidade foram os únicos a serem objeto de alguma previsão urbanística de longo prazo com relação à sua forma: mais largos, alguns possuem canteiro central. As demais ruas projetadas dos parcelamentos carecem de boas conexões com os parcelamentos vizinhos e são quase sempre estreitas (12 metros em média), tanto no leito carroçável ( 7 a 9 metros) como nos passeios (2,5 a 1,5 metros de cada lado, raras as de 3 ou mais metros de largura). Essa padronização tem sido repetida nas sucessivas posturas municipais. A prefeitura pouco ou nada tem feito para atualizar os parâmetros de projeto dos arruamentos, de maneira a levar em consideração as mutações nas formas de mobilidade (crescimento da frota de veículos), dos índices de adensamento populacional e construtivo (verticalização), concentração de atividades (centralidades) e da infra-estrutura (fiação elétrica, dutovias, cabeamentos). Portanto, daí se constata que, quando as ruas são implantadas, muito pouco sobra para o tratamento paisagístico, de modo a assegurar as funções de percolação, sombreamento, ajardinamento e passeio. Não sendo fiscalizadas pela prefeitura, as ações individuais de 
execução dos passeios resultam - quando efetivamente executadas em acabamentos arbitrários, fragmentados, repletos de barreiras físicas, arborização insuficiente e inadequada quanto à sua localização e espécies implantadas, entre outros problemas existentes. Nessa condição, não é incomum caminhar-se, preferencialmente, pela pista de veículos ao invés de utilizar-se os passeios. O perfil transversal das ruas modificou-se ao longo do tempo, seguindo as tendências verificadas nas principais cidades brasileiras, particularmente com a exigência dos recuos frontais os quais, por muito tempo, ficaram visualmente incorporados à paisagem viária. Em toda a área urbana verifica-se a tendência ao enclausuramento da paisagem das ruas, resultado da construção de muros altos e fechados e, no caso dos edifícios, com a construção de guaritas e coberturas de garagem semi-subterrâneas, ocupando toda a área do terreno. Nessas áreas, os espaços livres públicos encontram-se claramente separados dos privados. O espaço, reduzido a mero corredor de passagem, árido e sem atrativos a estimularem o "passear", suscita insegurança nos pedestres que, sem a presença solidária dos moradores, tornam-se vulneráveis a atos de violência.

b) As praças. Maceió dispõe de "cerca (sic) de 200 áreas verdes, das quais 154 são praças, 24 são canteiros, além de 12 mirantes" (Gazeta de Alagoas, p. D4, 19/08/2007). A falta de precisão no número é um sintoma do desconhecimento reinante sobre a dimensão exata do patrimônio público representado por esses tipos de áreas públicas. Esse número se refere aos espaços "oficiais", reconhecidos e monitorados pela administração municipal. Eles são encontrados, principalmente, nas partes habitadas pela população de renda média e alta, nos bairros mais antigos e nos conjuntos habitacionais. As primeiras praças da cidade, as mais centrais, foram demarcadas já quando de seu primeiro plano urbanístico, em 1821. Dessas, resta metade de suas áreas originais; a outra metade foi ocupada com instituições públicas (palácio, teatro). Com a Lei n. 6.766/79, a obrigatoriedade de prover os loteamentos com praças, áreas verdes ou áreas de preservação fez com que a cidade pudesse voltar a ter espaços nos novos tecidos urbanos destinados para o convívio dos vizinhos, embelezamento, conforto e dinâmica natural (ventos, insolação-sombreamento, drenagem, fauna). Esse requisito era uma exigência praticamente inexistente para a aprovação de empreendimentos imobiliários entre os anos 40 e 70 , período de grande expansão do tecido urbano. A não-execução de projetos apropriados e o descuido com relação à manutenção desses espaços tornaram muitas áreas de praça objeto de "doações", passando a abrigar templos, equipamentos coletivos públicos (escolas, postos de saúde, mercado) ou privados (clubes, templos) ou, então, quando não eram invadidas, tivessem seus usos modificados. Muitas dessas áreas permanecem 
sem implantação e adequação ao uso, sobretudo nos bairros populares, identificados pela população como "terra de ninguém", eventualmente sendo apropriados pelos moradores próximos para "campos de pelada" e outros usos. Maceió é, hoje, uma cidade carente de praças, tanto quanto de espaços viários mais generosos para mitigar o clima tropical úmido e propiciar locais de sensibilização paisagística, lazer e socialização dos habitantes. Todavia, essa carência parece ser aparente, pois a tendência contemporânea de retraimento dos indivíduos aos seus espaços privados - entre outros motivos por insegurança nos logradouros públicos — tem resultado no abandono dos locais de convivência citadina. Dentre as praças e áreas verdes públicas projetadas nas últimas décadas, as mais significativas localizam-se em conjuntos habitacionais populares (Figura 11). Nos loteamentos privados elas tendem a ser áreas residuais ou localizadas nos terrenos mais inclinados ou "de fundos", isto é, descentralizados com relação aos acessos e fluxos principais (Figura 12).

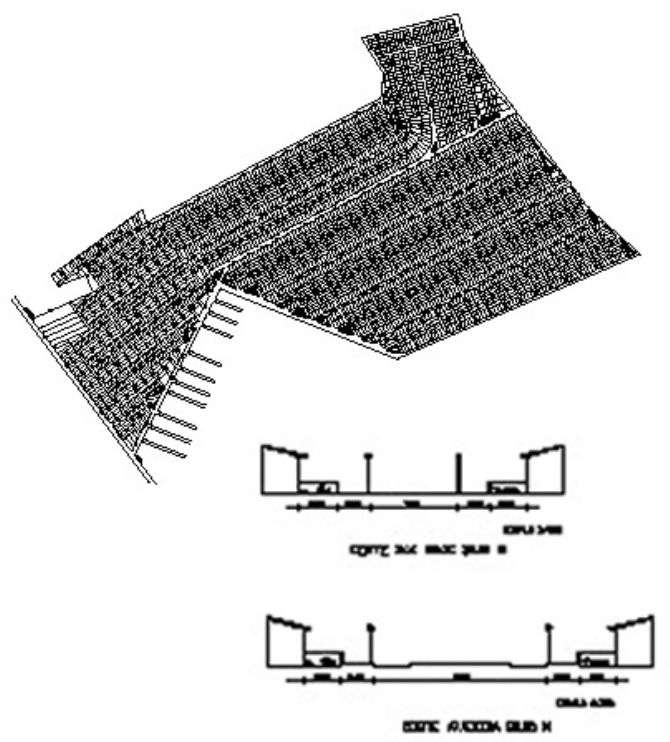

Figura 12:

Exemplo de grande loteamento com áreas de praças em terrenos residuais na periferia da gleba

Fonte: FARIA et al, 2006

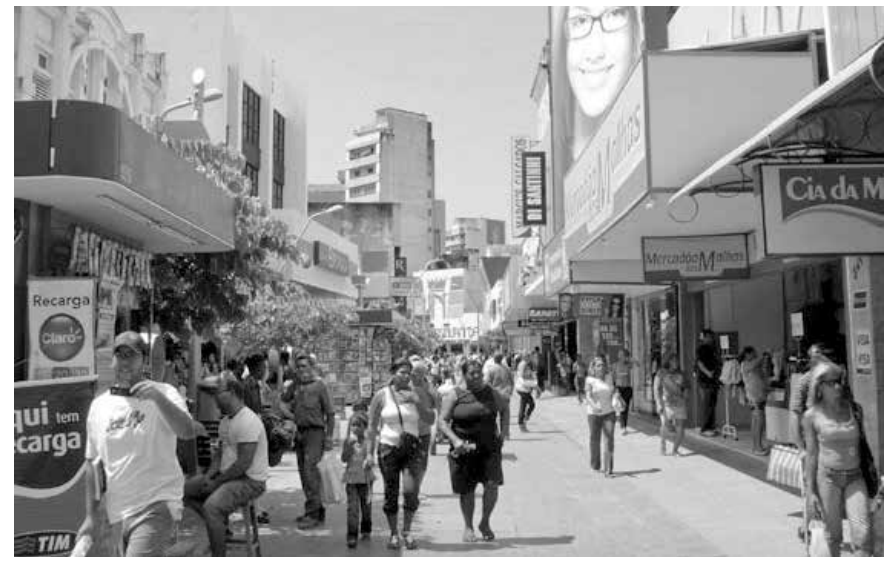

Foto 13:

Calçadão do Centro Histórico de Maceió após requalificação paisagística Crédito: Foto de Geraldo Faria, 2008 
c) Os "parques". A cidade dispõe de apenas um parque municipal, vegetado, aberto ao público, com tratamento paisagístico rudimentar pouco atrativo para integrá-lo ao cotidiano da cidade. Em compensação, o município dispõe da longa faixa costeira com suas praias acessíveis, as mais densamente povoadas, contando com extensas áreas trabalhadas em termos de cuidados paisagísticos que as configuram como os principais "parques" da cidade. São as principais atrações naturais da cidade às quais a população acorre de longas distâncias nos fins de semana e feriados. Deve-se ter em conta que, no território municipal, localizam-se também grandes extensões de áreas vegetadas contínuas sob proteção do poder público (mananciais, mangues, grotas), com grande potencial paisagístico natural, que podem ser integradas à cidade como áreas acessíveis ao desfrute do público para lazer. Dentro da categoria de "parque" enquadra-se, por suas dimensões e complexidade, o espaço denominado "Corredor Cultural Vera Arruda", com um programa complexo o qual visa celebrar o prestígio intelectual de personalidades alagoanas. Isso foi realizado por meio de um projeto paisagístico implantado na grande "área verde" central de um loteamento concebido nos moldes da "unidade de vizinhança" de Perry, adequando-o não apenas como espaço de circulação e lazer, mas também como atração cultural para toda a cidade, com esculturas, alegorias e painéis biográficos de personagens notáveis da cultura de Alagoas. Também, mas sem a intenção de constituí-las como parques urbanos, existem as lagoas (tanques) de retenção de drenagem das águas pluviais, implantadas no tabuleiro norte nas cotas mais baixas de uma grande bacia endorréica, localizadas em área de intenso processo de urbanização.

7. Áreas privativas e institucionais não-edificadas. Dentre os espaços não-edificados constituintes dos domínios privados, mas que, de alguma forma, integram-se à paisagem dos espaços de domínio público, ampliando-o, podemos citar os seguintes: (a) servidões e recuos das edificações no interior dos lotes; (b) sítios e chácaras; (c) associações recreativas, hotéis-resorts, instituições; e (d) lotes e glebas não-edificados. Esses ambientes conferem porosidades ao espaço, pois, por meio deles permeiam-se os elementos da atmosfera (vento, luz solar, umidade) e da biosfera (insetos, animais, pólen).

a) Servidões e recuos. As servidões são áreas non aedificandi de interesse público, localizadas no interior dos lotes urbanos e rurais, cuja utilização e cuidado cabem aos proprietários. Os determinantes da existência dessas áreas - sua dimensão, configuração e localização — são de diversas ordens: ambiental-ecológica, paisagística, saneamento, habitabilidade, infra-estrutura, acessibilidade-mobilidade comunitária (passagens) e de ordem econômica. Uma configuração de servidão pública, de natureza especificamente urbana, são os recuos das edificações, obrigatórios ou 
não. De um modo geral, a exigência e a configuração dos recuos têm seguido os parâmetros exigidos nas principais capitais brasileiras, sem uma notável particularização para Maceió. Entretanto, mudam as funções e os usos. As áreas de recuo da edificação, mais significativas para a paisagem de Maceió, são os jardins frontais e os quintais, especialmente nos lotes residenciais. Dois fenômenos têm contribuído para enfatizar os efeitos esperados dos recuos: 1) o processo de verticalização das edificações; 2) o enclausuramento e o amuralhamento das propriedades. Com o processo de verticalização das edificações, os debates públicos sobre os parâmetros fixados no código de urbanismo - conforme a ordem cronológica de seu aparecimento na mídia - têm se centrado sobre, pelo menos, quatro fenômenos ou impactos: a) a altura das edificações na planície litorânea e a conseqüente obstrução da visibilidade do facho sinalizador do farol oceânico; b) a ampliação do volume edificado com o bloqueio da ventilação natural e seus impactos sobre dispêndio de energia e conforto térmico; c) a obstrução dos mirantes naturais de contemplação da paisagem; e d) o devassamento da intimidade dos apartamentos com a proximidade das edificações. Entretanto, não se tem discutido os impactos do sombreamento das áreas públicas ou privadas vizinhas aos edifícios, visto que, em Maceió, o sombreamento das edificações pode ser considerado como positivo em determinadas circunstâncias. Quanto ao fenômeno do amuralhamento das propriedades, constata-se a crescente ocultação dos quintais, jardins e fachadas frontais das edificações aos olhares dos passantes, em especial em relação ao espaço da rua, restringindo-o, tornando-o confinado e inóspito como longos corredores estreitos, desinteressante como paisagem. A generalização do uso de dispositivos do gênero "pega-ladrão" (arames farpados, fios eletrificados, cacos de vidro, grampos), contribui para criar uma paisagem marcada por sinais peremptórios e agressivos de "mantenha a distância" para os "estranhos", como forma de afirmar que qualquer tentativa de desrespeito ao patrimônio privado e às regras de convívio (ao autocontrole da violência) será evitada com barreiras físicas contundentes. Atitudes reativas de ampliação do nível de segurança das propriedades têm levado os moradores a eliminar as já escassas árvores dos passeios - ou a substituí-las por árvores de pequeno porte — , reforçando, desse modo, o já mencionado efeito corredor das ruas. Os recuos dos prédios, por sua vez, passam a ser totalmente ocupados e impermeabilizados para a implantação das garagens, halls e terraços muito acima do nível do passeio. Mantidos os recuos padrões, sem serem estes ampliados em função do aumento da altura das edificações, o efeito de confinamento das áreas públicas e servidões com a ocultação da abóbada celeste e dos espaços laterais torna-se quase absoluto. 
b) Sítios e chácaras. Inseridos na malha urbana subsistem inúmeros sítios e chácaras, resultantes de parcelamentos antigos ou de remembramentos utilizados para residência permanente ou lazer familiar. Parte desses terrenos situa-se próxima a bordas de ravinas, englobando, assim, áreas do platô e de encostas, e outra parte são grandes lotes de empreendimentos suburbanos, granjas, nos quais há grandes áreas vegetadas com árvores frutíferas ou pequenas culturas, ou ainda pequenas criações; outros são campos desmatados, utilizados com freqüência para o pastoreio de animais; outros ainda subutilizados ou "vazios", aguardando valorização. As chácaras podem ser notadas na paisagem suburbana pela vegetação exuberante, todas cercadas com muros altos. $\bigcirc$ processo de extensão da malha urbana por meio de parcelamentos apresenta, ainda, muitas descontinuidades. Todavia, aquele já alcançou e transpôs as localidades dos empreendimentos de chácaras, induzindo o desmembramento das mesmas em pequenos lotes formando vilas, vendidos para faixas menores de renda — inclusive vilas ("quartinhos" de aluguel), sem acréscimo de novas áreas de uso coletivo (exceto os acessos) e com elevadas taxas de ocupação do solo.

c) Associações recreativas, hotéis-resorts, instituições. São atividades que requerem ou dispõem de grandes áreas não-edificadas, impermeabilizadas ou não. As associações, em geral, dispõem de campo de futebol grande ou pequeno, área para brinquedos infantis, piscina, jardins com canteiros, arborização. Com acesso restrito aos associados, algumas associações (e clubes) fazem locação de seus ambientes e equipamentos para eventos particulares. Hotéis-resorts têm ocupado áreas de praia junto da desembocadura de riachos nos quais se encontram mangues. Essas ocorrências são, em parte, conservadas como elementos paisagísticos dos empreendimentos e, dessa maneira, integram-se também à paisagem urbana. $\bigcirc$ caso da lagoa da Anta junto do Hotel Jatiúca é exemplar.

d) Lotes e glebas não-edificados. Maceió é uma cidade com muitos terrenos não-ocupados. São grandes glebas sem uso produtivo, inclusas na malha urbana, vazios que, amiúde, são utilizados para "campos de futebol" pelos moradores de loteamentos e conjuntos periféricos. São lotes ou grandes glebas intersticiais que, inclusive, iá contam com alguma facilidade de conexão à infra-estrutura urbana instalada (água, energia, transporte). Não se consideram, aqui, os terrenos impróprios à ocupação, tais como as encostas dos tabuleiros, áreas alagáveis e faixas de domínio (servidão). É interessante registrar que terrenos localizados em áreas loteadas e deixados ao abandono são, eventualmente, apropriados pela vizinhança para a instalação de espaços de convívio, com o objetivo de manter esses terrenos "limpos", isto é, sem mato, sem animais peçonhentos, apropriados contra a intrusão de estranhos à vizinhança. Atitude rara, mas que começa a ocorrer com mais freqüência na cidade. 


\section{2 - A SOCIABILIDADE PÚBLICA EM MACEIÓ}

Abstrair do complexo de formas materiais que configuram os espaços de uma grande cidade seus espaços livres de edificações, para observá-los, simultaneamente, como um sistema paisagístico-ambiental e como locais densos de práticas de sociabilidade urbana que possam ensejar o desenvolvimento de uma esfera pública - especialmente aqueles espaços de uso comunitário ou público - impõe, antes de qualquer coisa, verificar quais tipos de relações sociais engendram, efetivamente, a constituição de públicos. Isso porque a condição de "ser público" não é tão evidente quanto possa parecer ou que se deseje que seja nem é equivalente ao conjunto da sociedade, principalmente em uma sociedade dividida em classes sociais.

Primeiramente, as praças estão deixando de ser espaços de afluência de público como lugar de "passatempo", enquanto as ruas se destinam cada vez mais a cumprir a função de meio para a mobilidade mecânica. Do público que freqüentava as praças restam apenas os passantes cotidianos e os "sem-teto" e "meninos e meninas de rua". Esses espaços passam a ser vistos como de exclusão social, perigosos para o passeio ou a permanência, à exceção de algumas poucas recentemente implantadas que chamam a atenção por sua vitalidade. Estas se situam em áreas muito adensadas e recebem uma manutenção cuidadosa. Aquelas mais centrais são também lugares de disputa de "pontos" pelos vendedores ambulantes. No início dos anos 90 a prefeitura tomou a iniciativa de cercar o entorno das praças centrais, de modo a fechá-las à noite e inibir o acesso diurno dos camelôs e pedintes. A manutenção das praças se faria em parceria com empresas privadas, no modelo de "adoção". Não obstante apoiada por parte da população, durou pouco tempo a medida, logo derrubada pela Justiça e pelas administrações seguintes, de orientação mais popular.

A prática da flânerie no centro comercial subsiste, praticada pelos segmentos populares, clientela dominante das lojas. Os segmentos de média e alta renda transferiram seu lugar de passeio e compras para estabelecimentos exclusivos, os shoppings e supermercados, a exemplo do que acontece em todo o país. No centro histórico e comercial persistem, ainda, muitas instituições públicas responsáveis pela polarização que a área ainda exerce sobre a cidade, não obstante destituída das atividades de moradia. É no calçadão do centro que as trupes de artistas mambembes, grupos de teatro locais e artistas populares montam seus espetáculos habituais. É no centro que ocorrem também as principais manifestações políticas.

Nas ruas, os passeios são impróprios para o transitar do pedestre e inacessíveis aos portadores de necessidades especiais. A mobilidade nesses espaços é fortemente dominada pelos meios mecânicos e rápidos, realizada utilizando-se automóveis e táxis - com vidros escurecidos, motos e serviço precário de ônibus. Carroças de frete e numerosas bicicletas sobrevivem a contragosto dos motoristas apressados. Espaços dos terrenos vagos, recuos de propriedades e frentes de estabelecimentos comerciais são tomados por painéis de propaganda que escondem a paisagem construída e porções das áreas vegetadas. As paisagens das ruas dos bairros residenciais de maior 
renda, vazias de gente, delimitadas por muralhas encimadas com dispositivos agressivos, são cada vez menos convidativas ao desfrute e à permanência. Percebe-se que as formas de relacionamento face a face entre os citadinos vêm sendo transferidas para espaços fechados ou substituídas pelo telefone. Mesmo assim, algumas ruas e caminhos de bairros residenciais ainda são os principais espaços de interação social entre vizinhos, entre grupos de amigos e colegas, de jogos infantis, de festas populares (arraiais, procissões), porém com tendência a deixar de abrigar essas atividades. Para - lazer popular e para exercícios físicos (caminhar, correr) utiliza-se, principalmente, a praia e os passeios ("calçadões") implantados na orla, locais onde ocorre a maior afluência de público e as pessoas se sentem mais protegidas. Nos bairros, onde não tem pista ou calçada, utiliza-se o próprio leito carroçável da rua, preferencialmente as mais movimentadas, cedinho ou no final da tarde, com riscos de atropelamento.

No âmbito das ações sobre a sociedade (política e cultura), à exceção dos espetáculos destinados ao entretenimento da massa e aos comícios eleitorais, muito pouco do que ocorre tem por cenário os espaços livres da cidade. Dois lugares ou circuitos são normalmente utilizados para as manifestações políticas: o anel central do centro histórico - onde se concentram as principais instituições públicas estaduais e municipais - e a avenida beira-mar nos bairros da Pajuçara à Jatiúca. Ultimamente, a tática de chamar a atenção de maior impacto utilizada pelos movimentos populares tem sido a de interromper a mobilidade urbana pela instalação de barreiras (queima de pneus velhos, por exemplo) em pontos nevrálgicos da cidade.

Poucas feiras populares permanentes ao ar livre sobrevivem com dinamismo. Lugares de compra, troca e escambo na periferia do centro comercial e dos antigos mercados ou em alguns bairros populares da periferia (feira dos camelôs, do Passarinho, do Rato, do Tabuleiro) polarizam uma clientela e cumprem um papel importante na estruturação da cidade. Em Maceió as feiras de rua não sobreviveram ao tempo; os supermercados e quitandas preencheram a função. Também os "churrasquinhos" (pequenos bares temporários ao ar livre), os quais substituíram, em parte, os antigos "passaportes" (como são chamados os trailers nos quais se vendem sanduíches), tiveram um importante crescimento nos últimos anos, tanto em número como em distribuição territorial pela cidade. Promovem animação nos "pontos" em que se instalam, sendo vistos com intolerância pelo poder público, com o objetivo de utilizarem passeios e ruas e não disporem de instalações sanitárias. Já os vendedores "porta a porta" de produtos perecíveis (peixe, camarão, hortaliças, frutas, macaxeira, quebra-queixo, sorvetes) intensificaram-se e diversificaram-se, decorrentes do desemprego nas últimas duas décadas. Eles contribuem para animar as ruas dos bairros residenciais com seus pregões característicos, alternando-se com os entregadores de água, gás engarrafado, correios, pedintes, fiscais e verificadores de consumo de água e luz, serviços móveis de propaganda sonora, com seus potentes autofalantes e os vendedores de mercadorias populares.

Por último, as grandes extensões de espaços livres apropriados para o uso da comunidade concentram-se junto da orla litorânea, locais onde inúmeros bares, restaurantes e outros comércios obtêm permissão de instalação em quiosques padro- 
nizados. Funcionando com música ambiente, entram em conflito com os moradores da vizinhança incomodados com o som em alto volume. As demais áreas da cidade, particularmente as localizadas na periferia norte da cidade, não obstante a proximidade de grandes áreas com potencial de utilização para o desfrute da população, ainda são completamente desprovidas de parques. Contam tão somente com umas poucas praças pobremente ambientadas ou com terrenos "vazios" nos quais inúmeros "campos de pelada" improvisados servem de espaços de sociabilidade. Esses, depois das ruas, são "equipamentos" imprescindíveis de lazer e sociabilidade para grande número de moradores, especialmente nos bairros residenciais periféricos que carecem de áreas de recreação e convívio. Onde há terreno vazio acessível pode surgir um "campinho" em chão batido e seus times "da casa", inclusive com traves e camisas doadas por político, autoridade ou comerciante das proximidades. Em levantamento, efetuado com base em mapa digital de 2000, contou-se 475 campos de pelada espalhados pela cidade. Nas conjunturas desfavoráveis de emprego, quando muitos ficam sem atividade, os campos de futebol exercem a função de passatempo e lugar de interação social e informações, estas muito úteis para as iniciativas dos indivíduos.

\section{3 - AS AÇÕES DO PODER PÚBLICO NA ÚLTIMA DÉCADA}

As sucessivas administrações municipais não têm conseguido superar as limitações estruturais, de ordem administrativa e financeira, para realizar investimentos na qualificação e adequação dos espaços livres necessários ao crescimento e aperfeiçoamento da economia e da sociabilidade urbanas. Em razão disso, os principais investimentos feitos em volume de recursos, nos últimos anos, concentram-se nas áreas de maior interesse turístico e nos pontos de maior fluxo de pedestres.

Do ponto de vista de uma gestão estratégica, Maceió tem sido identificada como destino turístico nacional e internacional de médio porte, o que contribuiria para dinamizar a relativamente frágil economia local com a geração de empregos, atração de divisas e investimentos privados e federais. Com a diminuição das expectativas de industrialização que nutriam as políticas desenvolvimentistas das décadas anteriores, as atividades de comércio, serviço e turismo têm sido enfatizadas desde os anos 80, ganhando maior importância nos últimos anos. Essa ênfase é constatada tanto na imprensa cotidiana como nos estudos realizados para o planejamento da administração pública, com consultoria nacional e internacional. Complementarmente, investimentos têm sido efetuados também no sistema viário, de maneira a melhorar a fluidez do tráfego de veículos com ênfase no transporte individual.

As ações efetivas do poder público municipal, especificamente sobre os espaços livres de Maceió — isto é, não considerando as ações sobre outros setores dos serviços públicos - podem ser, grosso modo, classificadas nos seguintes tipos: 1) pavimentação e drenagem de ruas; 2) implantação de meios de acesso a grotas habitadas (escadarias); 3) reforma e melhoramentos paisagísticos dos parques litorâneos; 4) construção de passagens de nível e contornos de quadra em importantes cruzamentos viários; 
5) reforma e embelezamento dos passeios dos bairros históricos (Jaraguá e Centro) (Figura 13) e pontos turísticos (Pajuçara, Jatiúca, Avenida); 6) combate sistemático à ocupação das ruas centrais pela atividade de comércio ambulante; 7) reforma e recuperação de praças e canteiros com a instalação de objetos de arte e construção de monumentos; 8) implantação do projeto de algumas praças, com destaque para o Corredor Cultural Vera Arruda (parcialmente implantado no bairro litorâneo da Jatiúca); 9) melhoramento do parque municipal, de modo a torná-lo atrativo para o uso.

No que toca às iniciativas de definição e de organização das ações do poder público de maneira mais global, devem ser mencionadas três delas pela ênfase na mobilização da opinião pública e de segmentos da esfera privada. Dessas, uma resultou em instrumentos normativos efetivos para a qualificação dos espaços livres da cidade. Trata-se do Plano Diretor Municipal (2005), complementado com os Códigos de Edificações e de Urbanismo (2007). Nesses, merecem destaque a definição e criação de "Zonas de Interesse Ambiental e Paisagístico", assim como um aperfeiçoamento e ampliação da definição de "Utilização dos espaços de uso público", contemplando vários aspectos e dispositivos legais destinados a incentivar a qualificação das áreas públicas. As outras duas iniciativas foram os estudos para um planejamento estratégico da cidade, coordenadas pela prefeitura de Maceió, uma delas com consultoria internacional catalã. Em termos setoriais devem ser mencionados dois projetos visando à requalificação paisagística e funcional dos bairros históricos (Jaraguá e Centro) e os projetos de melhoramento paisagístico das orlas lagunar e litorânea - alguns com sucesso, outros apenas parcialmente implantados.

Embora muitas das ações propostas nos estudos não tenham sido executadas, percebe-se, claramente, uma preocupação em expressar um sentido de "modernidade" à paisagem dos espaços de uso público localizados nos bairros, a receberem mais investimentos por meio do mercado imobiliário e onde se concentram as atividades e expressiva proporção de moradias dos grupos de maior renda. Nesses têm sido implantados dispositivos decorativos (esculturas e monumentos), semáforos sofisticados, sinalização de trânsito, jardins, quadras esportivas, pistas para caminhadas, ciclovias, manutenção dos canteiros das principais vias, cruzamentos em viadutos, substituição de pavimentos, postes com design futurista, fiação elétrica subterrânea ou "revival", orelhões geométricos, abrigos metálicos, entre outros.

Todavia, pouco foi efetivado com relação à limpeza e tratamento dos espaços livres periféricos, assim como de combate à polvição de bacias hidrológicas e massas d'água e à degradação continuada das áreas não-edificáveis. Praticamente nada foi realizado para a adequação dos passeios às necessidades de locomoção dos pedestres, em geral, e de tratamento paisagístico adequado ao clima e aos ciclos naturais.

\section{4 - O SISTEMA DE ESPAÇOS LIVRES DE MACEIÓ: UMA SÍNTESE}

Os aspectos sistêmicos mais importantes dos espaços livres foram caracterizados sob diversos enfoques nos itens anteriores e analisados caso a caso. Para isso, 
abordou-se os aspectos que reputamos mais importantes, concernentes à totalidade da cidade no que diz respeito às relações entre espaços livres, urbanização, formação social, paisagem urbana e esfera pública. Como conclusão, cabe, agora, esboçar uma síntese que procure reconstruir o quadro geral e torne evidentes suas tendências mais significativas.

Nas análises realizadas, não se procurou deter em evidenciar as possíveis determinações das formas dos espaços que poderiam resultar em sintaxes espaciais particulares ou globais utilizadas na conformação dos espaços livres da cidade. Estudos dos projetos de parcelamento implantados durante a segunda metade do século passado (FARIA et al, 2004, 2005, 2007) permitem afirmar que diversos foram os princípios ordenadores da organização do espaço, assim como variadas foram as sintaxes espaciais utilizadas. Disso resultou um espaço urbano constituído de um elenco significativo de fragmentos de invenções de paisagem os quais acompanham, muito de perto, as tendências em voga no pensamento urbanístico do espaço, contemporâneo, para se referir apenas ao tecido urbano legal. Assim, encontra-se, em Maceió, desde soluções de radical "anticidade", inserida dentro da cidade, como no caso de loteamento em chácaras florestadas, ao embrião da mais densa urbanização na qual a verticalização avança a passos rápidos com todos os seus avatares em termos de desfuncionalidades, tensões sociais e artificialismo, passando-se pelas diversas combinações de relações entre natureza, carências (e potencialidades), artifício, atividades (trabalho), proximidades (e distanciamentos), lucros (e rendas fundiárias), memória (e devir), história (e mimese), cultura, segurança, temporalidades (e ritmos) com as espacialidades resultantes das singulares equações a que cada urbanista-paisagista chegou em cada projeto.

Isso posto, os aspectos sistêmicos que devemos evidenciar são os seguintes:

\section{1) Quantidade de espaços livres x área urbanizada}

Primeiramente, constata-se: à medida que o tecido urbano vai se consolidando com a ocupação dos lotes por construções e atividades, os espaços livres tendem a ser delimitados e confinados até assumirem o formato geométrico e repetitivo que lhes foi determinado pelos projetos de parcelamento: os espaços comunitários assumem a forma de corredores ou de largos e, os privados, as formas de espaços fragmentados e exíguos. As paisagens assim definidas, com variações de traçado e dimensões, configuram tanto o esquema como o sistema espacial típico de toda grande cidade, especialmente das áreas mais urbanizadas. A inevitável monotonia que a disposição serial e geométrica dos lotes e das ruas enseja é casual ou intencionalmente interrompida por largos ou praças, pela variação na altura das edificações e na largura dos recuos (quando estes são generosos e visualmente acessíveis), pela arborização, pela descontinuidade do tecido urbano, especialmente pelas mudanças bruscas de relevo, massas d'água, as grandes áreas de matas e chácaras remanescentes. $\bigcirc$ sistema dominante de configuração espacial utilizado para a produção do tecido urbano em Maceió é o de residências térreas, com ruas de largura apenas suficiente para 
o trânsito dos moradores. $\bigcirc$ processo de verticalização realiza o remanejamento do parcelamento original sem alterar em nada as dimensões das ruas.

\section{2) Distribuição das áreas livres e acessibilidade}

Considerando a cidade de Maceió em sua totalidade, constata-se a existência de grandes extensões de áreas não-urbanizáveis que lhe definem fronteiras bem delimitadas e também segmentações do tecido urbano. Essas áreas, em razão de suas características morfológicas e dinâmicas, devem ser institucionalizadas como de "proteção permanente" (APP), e instrumentos eficientes de manejo da ocupação das áreas não-urbanizáveis devem ser implementados para coibir sua degradação. A relação entre área urbanizada e área total de espaços livres indica que a cidade conta com a presença de significativas extensões as quais, adequadamente manejadas, poderiam ser incorporadas ao espaço da cidade como áreas minimamente ocupadas ou construídas em que predominariam, como atrações, a natureza e sua dinâmica servindo de meio para a experiência sensorial. Isso implica a necessidade de atribuir-lhes usos que tenham por princípio imperativo a conservação da dinâmica natural específica de cada uma delas e a acessibilidade coletiva. Referimo-nos às calhas naturais de drenagem e falésias - especialmente as que ainda conservam grandes áreas vegetadas —, às faixas costeiras litorâneas e às margens da laguna Mundaú. No sistema natural ocorre também a dinâmica da recarga dos aqüíferos, a qual não é perceptível senão em grande escala, e só recentemente começou a ser incorporada como fator de restrição à ocupação indiscriminada dessas áreas, porém ainda sem um projeto de manejo e paisagístico que incorpore essa dinâmica ao sistema de espaços livres.

Com relação às áreas livres projetadas, a relação entre quantidade de espaços livres e a área construída tende a ser diretamente proporcional à renda dos moradores no caso das construções térreas. No caso das áreas mais densas e verticalizadas, essa relação tende a tornar-se indiferente à variação da renda: abdica-se de parte dos espaços livres em proveito da densidade populacional e da economia.

\section{3) Sociabilidades e esfera pública}

As análises efetuadas indicam que poucas são as práticas sobre as áreas livres em Maceió as quais, além das questões de urbanidade e civilidade suscitadas pelo cotidiano, ensejam também a formação de uma consciência política preocupada com o devir. Elas acontecem, mas não são dotadas, a não ser raramente, de significação sobre o funcionamento das instituições.

Nesse aspecto é importante considerar que uma dada relação ou prática social não engendra, necessariamente, uma específica e singular localidade no mundo, senão em determinadas condições. Ela acontece onde os indivíduos concretos determinam que ela deva acontecer, conforme as circunstâncias que as ensejam e possibilitam. Algumas podem ser induzidas pelas condições nas quais os atores se encontram, tais como as de multidão ou de relativo ou momentâneo isolamento, ou as posições que os indivíduos 
ocupam mais continuamente na sociedade (divisão social do trabalho), os intercâmbios que realizam, etc.; muitas delas, porém, são repetições necessárias para a continuidade da vida e constituem a cultura. Quando reproduzidas continuadamente, aí sim, ensejam a regularização-apropriação das condições materiais (espaciais, ambientais, paisagísticas) nas quais se espera que elas devam normalmente (respeitando a norma) ou "naturalmente" acontecer. Também poucas são as relações sociais a engendrarem um público. Isso quer dizer que nem tudo o que é social e comunitário tem a qualidade de engendrar um público. Ademais, em uma sociedade dividida em classes — na qual as condições materiais e de autonomia dos indivíduos são muito desiguais, condições predominantes de vida, situando-se na linha das carências básicas e relações de poder assimétricas - , são poucas, segmentadas e, muitas vezes, excludentes as práticas contendo a potencialidade de gerar públicos no sentido político do termo, isto é, como momento do ser social atento e agindo sobre as questões de interesse geral. Mais difícil ainda quando a formação social é constituída por centenas de milhares de indivíduos, quando o espaço habitado fragmenta-se em inúmeras comunidades distintas, quando as relações políticas são formalmente mediadas por representantes profissionais e a opinião pública é manipulada por meios privados de comunicação. Nesse quadro de grandes limitações, as mudanças socioculturais e econômicas, a forte presença da natureza e algumas iniciativas individuais contribuem para a manutenção de uma relação excepcional entre áreas livres e áreas construídas.

\section{Nota}

(1) Por servidão ou recuo obrigatório, faz-se referência às superfícies não-edificáveis das propriedades definidas por legislação urbanística local que limita a taxa de ocupação dos terrenos com edificações. $\bigcirc$ recuo obrigatório frontal e, eventualmente, os laterais e de fundos, estão incluídos nessas limitações ao direito de construir e ocupar um lote urbano. Esses espaços se destinam a regular as densidades de construção e de população, assim como assegurar um mínimo de espaços destinados ao funcionamento da dinâmica da natureza em cada lugar (ventos, insolação, drenagem, fauna, vegetação), considerados pela cultura de cada localidade como indispensáveis para se obter alguma qualidade paisagística e ambiental para a vida humana. Denominamos essas áreas de "espaços de servidão", pois a razão de sua existência não é outra senão a de exigir a conformação de espaços não-edificáveis destinados a assegurar atender a determinadas necessidades que, intransferíveis, só podem ser servidas (supridas) em cada lugar.

\section{Bibliografia}

FARIA, Geraldo M. G.; CARVALHO, Marlise L. S.; SILVA, Tatiana S. da. A produção dos espaços de uso público da cidade de Maceió, de 1945 a 1960. Relatório de pesquisa, 1a etapa, Grupo de Estudos de Problemas Urbanos. Maceió: Gepur/Ufal/Fapeal, 2004

CARVALHO, Marlise L. S.; COSTA, Viviane R. A produção dos espaços de uso público da cidade de Maceió, de 1960 a 1970. Relatório de pesquisa, 2a etapa, Núcleo de Estudos Morfologia dos Espaços Públicos. Maceió: Mep/Ufal/Fapeal, 2005.

COSTA, Viviane R.; OLIVEIRA, Andreia da S.; ROCHA, Nikael F. da; SANTOS, Mônica C. X. dos; NASCIMENTO, Thássia C. A produção dos espaços de uso público da cidade de Maceió, de 1970 a 1980. Relatório de pesquisa, 3aㅡ etapa, Núcleo de Estudos Morfologia dos Espaços Públicos. Maceió: Mep/Ufal/Fapeal, 2007. 
